\title{
The NALP3 inflammasome is required for collagen synthesis via the NF- $\kappa B$ pathway
}

\author{
JU KUANG, MIN XIE and XIAOLIN WEI
}

Department of Respiratory Medicine, West China Hospital, Sichuan University, Chengdu, Sichuan 610041, P.R. China

Received May 1, 2017; Accepted January 8, 2018

DOI: 10.3892/ijmm.2018.3404

\begin{abstract}
The NALP3 inflammasome interacts with various immune and cell metabolic pathways and may participate in pulmonary fibrosis. However, little is known on its regulatory mechanism with respect to collagen synthesis. The objective of the present study was to investigate whether NALP3 inflammasome activation is involved in $\mathrm{H}_{2} \mathrm{O}_{2}$-mediated collagen synthesis, in addition to examining the possible cell signaling mechanisms underlying this effect. It was demonstrated that the $\mathrm{NF}-\kappa \mathrm{B}$ signaling pathway was activated under conditions of $\mathrm{H}_{2} \mathrm{O}_{2}$-mediated oxidative stress in NIH-3T3 mouse embryonic fibroblasts. $\mathrm{H}_{2} \mathrm{O}_{2}$-exposed fibroblasts exhibited activated NALP3 inflammasomes via increased NALP3, apoptosis-associated Speck-like protein and caspase-1 expression and the secretion of interleukin- $1 \beta . \mathrm{H}_{2} \mathrm{O}_{2}$ also elevated $\alpha$-SMA and type I collagen expression. In vitro silencing of NALP3 attenuated the degradation of $\mathrm{I} \kappa \mathrm{B} \alpha$ and decreased the synthesis of type I collagen. Furthermore, the NALP3 inflammasome was found to be activated in bleomycin-induced pulmonary fibrosis in mice, and this activation was relieved by a nuclear factor $(\mathrm{NF})-\kappa \mathrm{B}$ inhibitor. Taken together, these findings indicate that the NALP3 inflammasome is involved in $\mathrm{H}_{2} \mathrm{O}_{2}$-induced type I collagen synthesis, which is mediated by the $\mathrm{NF}-\kappa \mathrm{B}$ signaling
\end{abstract}

Correspondence to: Dr Min Xie, Department of Respiratory Medicine, West China Hospital, Sichuan University, Chengdu, Sichuan 610041, P.R. China

E-mail: huaxixiemin@163.com

Abbreviations: NF- $\kappa \mathrm{B}$, nuclear factor $\kappa \mathrm{B}$; IL-1 $\beta$, interleukin $1 \beta$; IL-18, interleukin 18 ; TGF- $\beta$, transforming growth factor- $\beta$; TNF- $\alpha$, tumor necrosis factor- $\alpha$; PDTC, pyrrolidine dithiocarbamate; ASC, apoptosis-associated Speck-like protein; I $\mathrm{B} \alpha$, nuclear factor of kappa light polypeptide gene enhancer in B-cells inhibitor $\alpha$; pNF- $\mathrm{B}$, phosphorylated NF- $\kappa \mathrm{B} ; \alpha$-SMA, $\alpha$-smooth muscle actin; BLM, bleomycin; IPF, idiopathic pulmonary fibrosis; ROS, reactive oxygen species; ECM, extracellular matrix; EMT, epithelial-to-mesenchymal transition; TLR, toll-like receptor 4; Ang-2, angiotensin 2; MMP-9, matrix metalloproteinase 9; CFs, cardiac fibroblasts; TECs, renal tubular epithelial cells

Key words: NALP3, NALP3 inflammasome, pulmonary fibrosis, $\mathrm{NF}-\kappa \mathrm{B}$ pathway, fibroblast pathway. Additionally, the NALP3 inflammasome contributes to the development of bleomycin-induced pulmonary fibrosis.

\section{Introduction}

Idiopathic pulmonary fibrosis (IPF) is a progressive and irreversible lung disease of unknown etiology, characterized by sequential episodes of acute lung injury with subsequent scarring. Pulmonary fibrosis may lead to respiratory failure due to damage to the lung structure and reduced gas exchange (1). No drugs are currently available that are able to control the accumulation of collagens in the lung once fibrosis has been established. Although several drugs have been applied to treat IPF, their clinical efficacy remains poor and the associated serious adverse effects pose problems during long-term treatment. Therefore, the development of novel therapeutic agents for this unmet medical need is required.

The NALP3 inflammasome represents the most extensively investigated inflammasome, and comprises a cytoplasmic multiprotein complex that consists of NACHT, LRR and PYD domains-containing protein 3 (NALP3), the adaptor protein apoptosis-associated Speck-like protein (ASC) containing a caspase recruitment domain (CARD), and pro-caspase-1, and interacts with various immune and cell metabolic pathways (2). Upon oligomerization, the NALP3 inflammasome activates the caspase- 1 cascade, which produces the active pro-inflammatory cytokines interleukin (IL)- $1 \beta$ and IL-18 when triggered by a range of molecules, ranging from pathogen-associated molecular pattern molecules to damage-associated molecular pattern molecules, which are involved in infection, tissue injury and metabolic dysregulation. Evidence suggests that the inflammasome is involved in the development of fibrosis. Specifically, inorganic particulates associated with the development of pulmonary fibrosis, such as asbestos (3), silica (4) and nanoparticles $(5,6)$, permeate lysosomal membranes, activating the NALP3 inflammasome, with subsequent IL-1 $\beta$ and IL-18 production. Furthermore, recent studies indicated that $\mathrm{NF}-\kappa \mathrm{B}$ mediates the reactive oxygen species (ROS)-induced NALP3 inflammasome by promoting the transcription of NALP3 and pro-IL-1 $\beta$ (7).

Bleomycin (BLM) is the chemotherapeutic agent most widely used to induce lung fibrosis in animal models and to identify the pathogenic mechanisms thereof, as the pathogenesis characteristics are very similar to those of IPF (8). Recently, NALP3 inflammasome activation in BLM-induced 
pulmonary fibrosis was reported by a series of studies (9-11). Specifically, BLM treatment has been shown to increase the production of ROS and uric acid (11), thereby inducing the development of lung fibrosis. In addition, these products have been shown in several cases to trigger NALP3 inflammasome activation. Furthermore, the purinergic receptor $\mathrm{P} 2 \mathrm{X} 7 \mathrm{R}$ is activated by ATP, which is released by injured lung cells following BLM treatment, leading to activation of the NALP3 inflammasome with subsequent cleavage and secretion of IL-1 $\beta$ and IL-18 (11,12). Notably, previous studies have demonstrated that a number of proinflammatory cytokines and profibrotic growth factors, including IL-1 $\beta$, IL-6, IL-18, tumor necrosis factor- $\alpha$ and transforming grow th factor (TGF)- $\beta$, are involved in pulmonary inflammation and fibrosis $(13,14)$. Recent studies, primarily focusing on inflammasome/IL-1 $\beta$ secretion axis-mediated inflammatory actions, further suggested that the NALP3 inflammasome mediates the development of fibrosis in systemic sclerosis $(15,16)$. NALP3 also appears to play a key role in promoting TGF- $\beta$ signaling and Smad $2 / 3$ activation in renal epithelial cells (17). However, although TGF- $\beta$ represents one of the most extensively investigated fibrogenic cytokines involved in the induction and development of pulmonary fibrosis, the mechanism underlying the role of NALP3 inflammasome in pulmonary fibrosis remains unclear.

Notably, an increasing volume of evidence indicates that NALP3 plays a key role in myofibroblast differentiation and collagen production in an IL-1 $\beta /$ Toll-like receptor 4

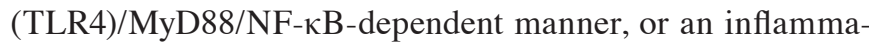
some-independent manner (18), as well as in liver fibrosis (19). Thus, in the present study, we hypothesized that the NALP3 inflammasome may participate in collagen production, and that $\mathrm{NF}-\kappa \mathrm{B}$ may serve as a link between NALP3 inflammasome activation and collagen synthesis.

\section{Materials and methods}

Cell culture, transfection and grouping. NIH-3T3 mouse embryonic fibroblasts were provided by the Laboratory of Stem Cell Biology, State Key Laboratory of Biotherapy, Sichuan University (Chengdu, China). The cells were cultured in Dulbecco's modified Eagle's medium (HyClone; GE Healthcare, Logan, UT, USA) supplemented with $10 \%$ fetal bovine serum (Sijiqing, Zhejiang, China) in a humidified atmosphere containing $5 \% \mathrm{CO}_{2}$ at $37^{\circ} \mathrm{C}$.

NALP3-siRNA (sense strand: 5'-CAGCCAGAGUGG AAUGACAdTdT-3'; antisense strand: 5'-UGUCAUUCCACU CUGGCUGdTdT-3') and negative control (NControl) siRNA were synthesized by RiboBio, Guangzhou, China. Transient transfections were performed using the HiPerfect Transfection Reagent (Qiagen GmbH, Hilden, Germany) together with either an NControl siRNA (10 nM) or NALP3-siRNA (10 nM), according to the HiPerFect Transfection Reagent instruction manual. At $12 \mathrm{~h}$ after transfection, the cells were treated with $\mathrm{H}_{2} \mathrm{O}_{2}(200 \mu \mathrm{M})$. The silencing efficiency of the NALP3-siRNA was determined using reverse transcription-polymerase chain reaction (RT-PCR) after $12 \mathrm{~h}$ of treatment. Approximately $24 \mathrm{~h}$ after $\mathrm{H}_{2} \mathrm{O}_{2}$ stimulation, total RNA was extracted for RT-PCR and, $48 \mathrm{~h}$ later, total protein was extracted for western blot analysis, and the cell supernatants were frozen at $-80^{\circ} \mathrm{C}$ for enzyme-linked immunosorbent assay (ELISA).
Additional groups of cells were treated with or without pyrrolidine dithiocarbamate (PDTC) (Sigma-Aldrich; Merck KGaA, St. Louis, MO, USA) $(50 \mu \mathrm{M}) 1 \mathrm{~h}$ prior to $\mathrm{H}_{2} \mathrm{O}_{2}$ stimulation. The cells and cell supernatants were collected in the same manner as described above.

Animals. A total of 42 male C57BL/6 mice (age, 8 weeks; weight, 20-24 g) were purchased from the Laboratory Animal Center of Sichuan University (Chengdu, China). The mice were housed ( $n=5$ per cage) in an air-conditioned animal facility under constant temperature and humidity, with a 12-h day-night cycle and free access to food and water. The mice were allowed to acclimatize for 2 weeks prior to the initiation of the experimental procedures. Animal experiments were performed according to protocols approved by the Laboratory Animal Welfare and Ethics Committee of the Sichuan University. Mice were randomly divided into three treatment groups as follows: i) BLM (Nippon Kayaku, Takasaki, Japan) + PDTC: On day 0 , a single intratracheal injection of BLM $(5 \mathrm{mg} / \mathrm{kg}$ in a final volume of $50 \mu \mathrm{l})$ was performed and PDTC $(100 \mathrm{mg} / \mathrm{kg})$ was intraperitoneally injected $2 \mathrm{~h}$ prior to the intratracheal injection. From day 1 onwards, PDTC (100 mg/kg) was intraperitoneally injected once daily. ii) $\mathrm{BLM}+$ phosphate-buffered saline (PBS): On day 0, a single intratracheal injection of BLM $(5 \mathrm{mg} / \mathrm{kg}$ in a final volume of $50 \mu \mathrm{l}$ ) was performed, and an equal volume of PBS was intraperitoneally injected $2 \mathrm{~h}$ prior to the surgery. From day 1 onwards, the same volume of PBS was intraperitoneally injected once daily. iii) Control group: A single intratracheal injection of PBS $(50 \mu \mathrm{l})$ plus intraperitoneal injections of PBS once daily. We utilized $10 \%$ chloral hydrate $(3.5 \mathrm{ml} / \mathrm{kg}$ intraperitoneally) to anesthetize the mice. The mice ( $\mathrm{n}=7 /$ group) were sacrificed at 7 and 28 days after BLM intratracheal injection.

Western blotting. Whole protein from cells or lung tissue was lysed with RIPA lysis buffer (Beyotime, Shanghai, China) in the presence of protease inhibitor cocktail (Roche, Mannheim, Germany) for $30 \mathrm{~min}$ and centrifuged at 12,000 x g for $20 \mathrm{~min}$ at $4^{\circ} \mathrm{C}$. Protein concentrations were determined using the bicinchoninic acid protein assay (Beyotime, Shanghai, China) according to the manufacturer's instructions. Equal amounts of protein $(60 \mu \mathrm{g})$ were separated by $10 \%$ sodium dodecyl sulfate-polyacrylamide gel electrophoresis and transferred to polyvinylidene difluoride membranes (Millipore, Billerica, MA, USA). The membranes were blocked in 5\% non-fat dry milk in $0.1 \%$ Tween-20, $1 \mathrm{X}$ Tris-buffered saline (TBST; $\mathrm{pH}$ 7.4) for $1 \mathrm{~h}$ at room temperature, and then incubated with goat anti-NALP3 antibody (ab4207; Abcam, Cambridge, MA, USA), rabbit anti-I $\mathrm{B} \alpha$ antibody (cat. no. 4812, CST, Danvers, MA, USA), rabbit anti-pNF- $\mathrm{B}$ antibody (cat. no. 3033, CST), rabbit anti-collagen I antibody (ab34710; Abcam), rabbit anti- $\alpha$-SMA antibody (ab5694, Abcam), or rabbit anti- $\beta$-actin antibody (bs-0061R; Bioss, Beijing, China) in blocking solution overnight at $4^{\circ} \mathrm{C}$, and washed three times with TBST at 10-min intervals. All above mentioned antibodies were diluted by $1: 1,000$. The membranes were then incubated with horseradish peroxidase-conjugated rabbit anti-goat (1:5,000; ZB-2306; ZSGB-Bio, Beijing, China) or mouse anti-rabbit IgG antibody (1:5,000; ZDR-5306; ZSGB-Bio) for $1 \mathrm{~h}$ at room temperature. After washing with TBST, antibody binding was 
Table I. Reverse transcription-polymerase chain reaction primers and products.

\begin{tabular}{lllc}
\hline Gene name & S/AS & \multicolumn{1}{c}{ Primer sequence (5'-3') } & Product size (bp) \\
\hline NALP3 & $\mathrm{S}$ & ATTACCCGCCCGAGAAAGG & 83 \\
& AS & TCGCAGCAAAGATCCACACAG & 78 \\
ASC & $\mathrm{S}$ & AATACAACCACTCGTACACGTC & 78 \\
& AS & AGCTCCAACCCTCGGAGAAA & 106 \\
Collagen-1 & $\mathrm{S}$ & GACAGTGCAACTGCGAGAAG & 91 \\
$\alpha$-SMA & AS & CGACTCCAGATAGTAGCTGACAA & 104 \\
$\beta$-actin & AS & GCTCCTCTTAGGGGCCACT & 245 \\
& S & ATTGGGGACCCTTAGGCCAT & \\
\hline
\end{tabular}

S, sense; AS, antisense; ASC, apoptosis-associated Speck-like protein; $\alpha$-SMA, $\alpha$-smooth muscle actin.

detected by electro-chemiluminescence using fluorescence detection equipment (ChemiDoc MP; Bio-Rad Laboratories, Inc., Hercules, CA, USA). The membranes were stripped using a buffer (10\% sodium dodecyl sulfate, $25 \mathrm{mM}$ glycine, $\mathrm{pH} 2.0)$ at room temperature for $30 \mathrm{~min}$, followed by washing in TBST for $30 \mathrm{~min}$. The membranes were blocked and reprobed for $\beta$-actin as a loading control.

Relative gene expression analysis. Total RNA was extracted from the lung tissue and from cells, using TRIzol reagent (Invitrogen; Thermo Fisher Scientific, Carlsbad, CA, USA) according to the manufacturer's instructions. RNA was reverse-transcribed into cDNA, using the ReverTra Ace qPCR RT kit (Toyobo Co., Ltd., Osaka, Japan). PCR was performed in a final volume of $10 \mu \mathrm{l}$ using a Thunderbird SYBR qPCR Mix (Toyobo Co., Ltd.). The cycling program involved initial denaturation at $95^{\circ} \mathrm{C}$ for $60 \mathrm{sec}$, followed by 40 cycles at $95^{\circ} \mathrm{C}$ for $15 \mathrm{sec}$ and $60^{\circ} \mathrm{C}$ for $60 \mathrm{sec}$. The $\beta$-actin gene was used as an internal control. NALP3, ASC, caspase-1, type I collagen and $\alpha$-smooth muscle actin (SMA) were detected. The sequences of the primers and products are listed in Table I. The relative expression of the genes was calculated by the $2^{-\Delta \Delta \mathrm{q}}$ method.

ELISA. The content of IL-1 $\beta$ in the lung tissue on day 28 after BLM instillation and in the cell supernatants was determined using an ELISA kit (ExCell Bio, Shanghai, China) according to the manufacturer's instructions.

Histopathological analysis. The tissue from the left lung was excised and immediately fixed with $4 \%$ paraformaldehyde for $48 \mathrm{~h}$, and then embedded in paraffin. Serial 4- $\mu \mathrm{m}$ paraffin sections were prepared using a rotator microtome. Sirius Red staining is considered as the optimal method for identifying tissue collagen, as it can differentiate between collagen types I and III, whereas Masson's trichrome staining is the classical method for staining collagen used by numerous studies. Masson's trichrome and hematoxylin-eosin staining were selected in the present study to estimate the degree of fibrosis, rather than differentiate between collagen types. The tissues were visualized under a Zeiss AX10 imager A2 microscope and captured using a Zeiss AX10 cam HRC (Zeiss, Oberkochen, Germany). The criteria for grading lung fibrosis were based on the modified Ashcroft score (20). The grade of fibrotic changes in each lung section was assessed as a mean score of severity from 10 randomly selected high-power fields.

Hydroxyproline assay. The levels of lung collagen were determined by analysis of the hydroxyproline content on day 28 after BLM infusion using a hydroxyproline assay kit (Jiancheng Institute of Biotechnology, Nanjing, China) according to the manufacturer's instructions.

Statistical analysis. All the results are shown as mean \pm standard error of the mean. Comparisons for multiple groups were performed by one-way analysis of variance followed by Tukey's multiple comparison test. For all analyses, a P-value of $<0.05$ was considered to indicate statistically significant differences.

\section{Results}

$\mathrm{H}_{2} \mathrm{O}_{2}$-induced collagen synthesis in mouse fibroblasts is mediated by the $N F-\kappa B$ signaling pathway. The I $\kappa \mathrm{Bs}$ is the most important inhibitor of NF- $\kappa \mathrm{B}$ activation and the degradation of $\mathrm{I} \kappa \mathrm{Bs}$ triggers $\mathrm{NF}-\kappa \mathrm{B}$ activation. Phosphorylation of $N F-\kappa B$ p65 at Ser536 is an indirect indicator of $N F-\kappa B$ activation, which results in translocation of the p65 subunit of NF- $\kappa \mathrm{B}$ to the nucleus (21). In the present study, detection of the $\mathrm{I} \kappa \mathrm{B} \alpha$ protein, which is the best studied $\mathrm{I} \kappa \mathrm{B}$ protein, and $\mathrm{pNF}-\kappa \mathrm{B}$, were used to estimate the degree of $\mathrm{NF}-\kappa \mathrm{B}$ activation. Western blot analysis of cell lysates revealed degradation of the I $\kappa \mathrm{B} \alpha$ protein and increase in pNF- $\kappa \mathrm{B}$ in the $\mathrm{H}_{2} \mathrm{O}_{2}$-treated group compared with controls. By contrast, the PDTC $+\mathrm{H}_{2} \mathrm{O}_{2}$ group exhibited preserved I $\mathrm{B} \alpha$ levels and decreased $\mathrm{NF}-\kappa \mathrm{B}$ 

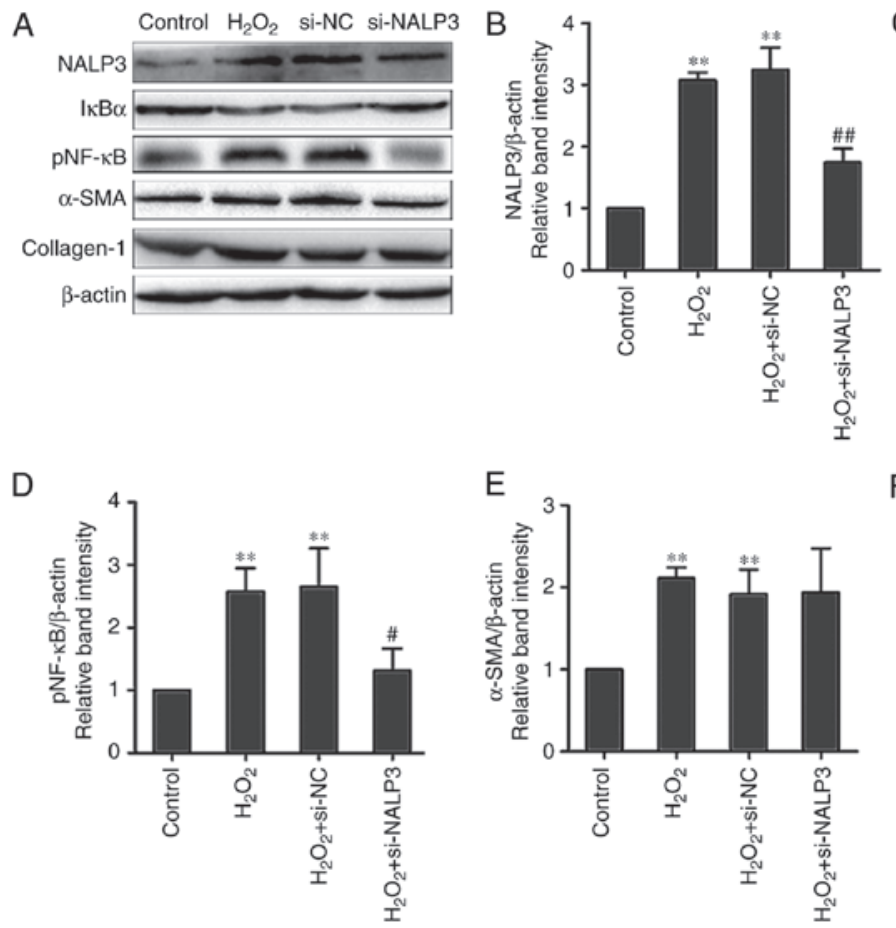

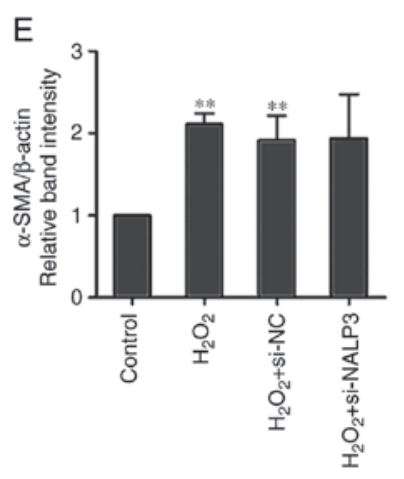

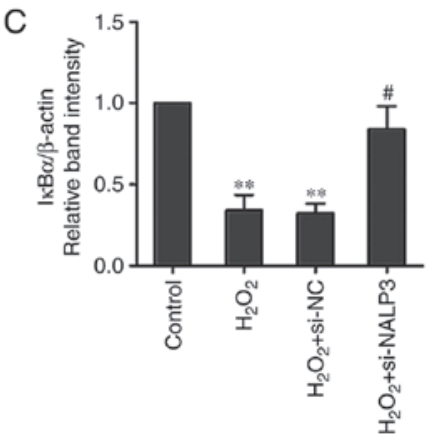

$\mathrm{F}$

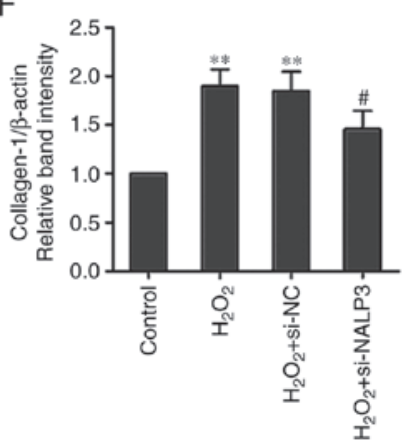

Figure 1. Anti-fibrotic effect of si-NALP3 on type I collagen synthesis through the NF- $\mathrm{KB}$ signaling pathway upon $\mathrm{H}_{2} \mathrm{O}_{2}$-mediated oxidative stress in fibro-

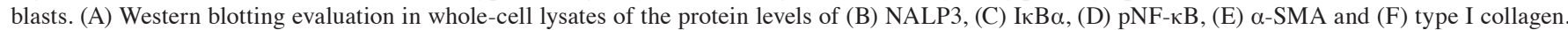
$\beta$-actin was used as a loading control. (B-F) The relative protein levels were quantified by scanning densitometry and were normalized to $\beta$-actin. Data shown represent the means \pm standard error of the mean of three experiments performed in duplicate. ${ }^{* *} \mathrm{P}<0.01$ vs. the control (treated with phosphate-buffered saline);

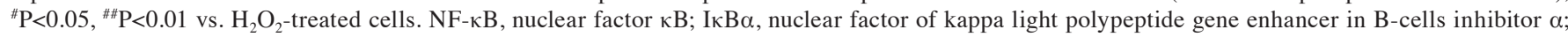

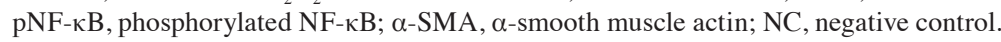

p65 phosphorylation (Fig. 1A, C and D). $\mathrm{H}_{2} \mathrm{O}_{2}$ is known to be an important regulator of oxidative stress. The results confirmed that NF- $\kappa \mathrm{B}$ was activated (Fig. 1A) via I $\mathrm{B} \alpha$ degradation during $\mathrm{H}_{2} \mathrm{O}_{2}$-mediated oxidative stress in fibroblasts. Stimulation with $\mathrm{H}_{2} \mathrm{O}_{2}$ significantly increased the expression of type I collagen at the mRNA and protein levels in NIH-3T3 cells (Figs. 1A and F, and 2A). Additionally, similar results for $\alpha$-SMA at the mRNA and protein levels were obtained at $24 \mathrm{~h}$ after treatment in the $\mathrm{H}_{2} \mathrm{O}_{2}$ group (Figs. $1 \mathrm{~A}$ and $\mathrm{E}$, and $2 \mathrm{~A}$ ). These findings demonstrated that $\mathrm{H}_{2} \mathrm{O}_{2}$ serves as an important regulator of extracellular matrix (ECM) deposition for fibroblasts by increasing type I collagen expression, and may be involved in the transition from fibroblasts to myofibroblasts by promoting $\alpha$-SMA expression. Furthermore, the upregulation of $\alpha$-SMA and type I collagen was inhibited by the antioxidant and NF- $\kappa \mathrm{B}$ inhibitor PDTC (Figs. 2A and 3A, E and F). Taken together, these data suggest that $\mathrm{H}_{2} \mathrm{O}_{2}$-induced oxidative stress stimulates type I collagen and $\alpha$-SMA production in mouse fibroblasts, and that NF- $\mathrm{KB}$ signaling is required in this process.

The NALP3 inflammasome plays an important role in $\mathrm{H}_{2} \mathrm{O}_{2}$-induced collagen synthesis in mouse fibroblasts via the $N F-\kappa B$ signaling pathway. Cells treated with $\mathrm{H}_{2} \mathrm{O}_{2}$ exhibited overexpression of NALP3, ASC and caspase- 1 at the mRNA level (Fig. 2A). In addition, $\mathrm{H}_{2} \mathrm{O}_{2}$ induced an increase in IL-1 $\beta$ content in cell supernatants, whereas cells treated with PDTC exhibited reduced expression of NALP3, ASC and caspase-1 mRNA and IL-1 $\beta$ content. The effect of PDTC on NALP3 protein levels was confirmed by western blot analysis. The results suggested that activation of the NF- $\kappa \mathrm{B}$ signaling pathway promoted NALP3 inflammasome activation by increasing NALP3, ASC and caspase-1 expression during $\mathrm{H}_{2} \mathrm{O}_{2}$-mediated oxidative stress (Figs. 2B and 3A-D). Furthermore, we demonstrated that the expression of NALP3 could be effectively knocked down using siRNA-NALP3, and that the mRNA levels of ASC and caspase-1 were downregulated when exposed to $\mathrm{H}_{2} \mathrm{O}_{2}$ under conditions of NALP3 knockdown. In addition, the secretion of IL-1 $\beta$ was also decreased. Inhibition of NALP3 abolished $\mathrm{H}_{2} \mathrm{O}_{2}$-mediated type I collagen synthesis and increased the mRNA levels of $\alpha$-SMA in fibroblasts. However, no effect on $\alpha$-SMA protein was observed following administration of siRNA-NALP3 (Figs. 1E and 3E). The I $\mathrm{KB} \alpha$ protein remained at a relatively high level and pNF- $\kappa B$ level was reduced compared with the siRNA-negative and $\mathrm{H}_{2} \mathrm{O}_{2}$ groups (Fig. 1A, C and D). Collectively, these findings suggest that activation of the NALP3 inflammasome is involved in $\mathrm{H}_{2} \mathrm{O}_{2}$-induced type I collagen production in fibroblasts via the NF- $\mathrm{KB}$ signaling pathway.

The NF- $\kappa B$ pathway is required for NALP3 inflammasome activation in BLM-induced pulmonary fibrosis. A single intratracheal injection of BLM constitutes a well-established animal model that results in airway epithelial cell damage, inflammation and formation of fibrotic lesions. In the present study, a well-alveolized normal histology was observed in the control group. By contrast, obvious alveolar wall thickening, massive infiltration of leukocytes and excessive deposition of mature collagen in the interstitium was observed in BLM-treated mice. Lung inflammation was contained on 


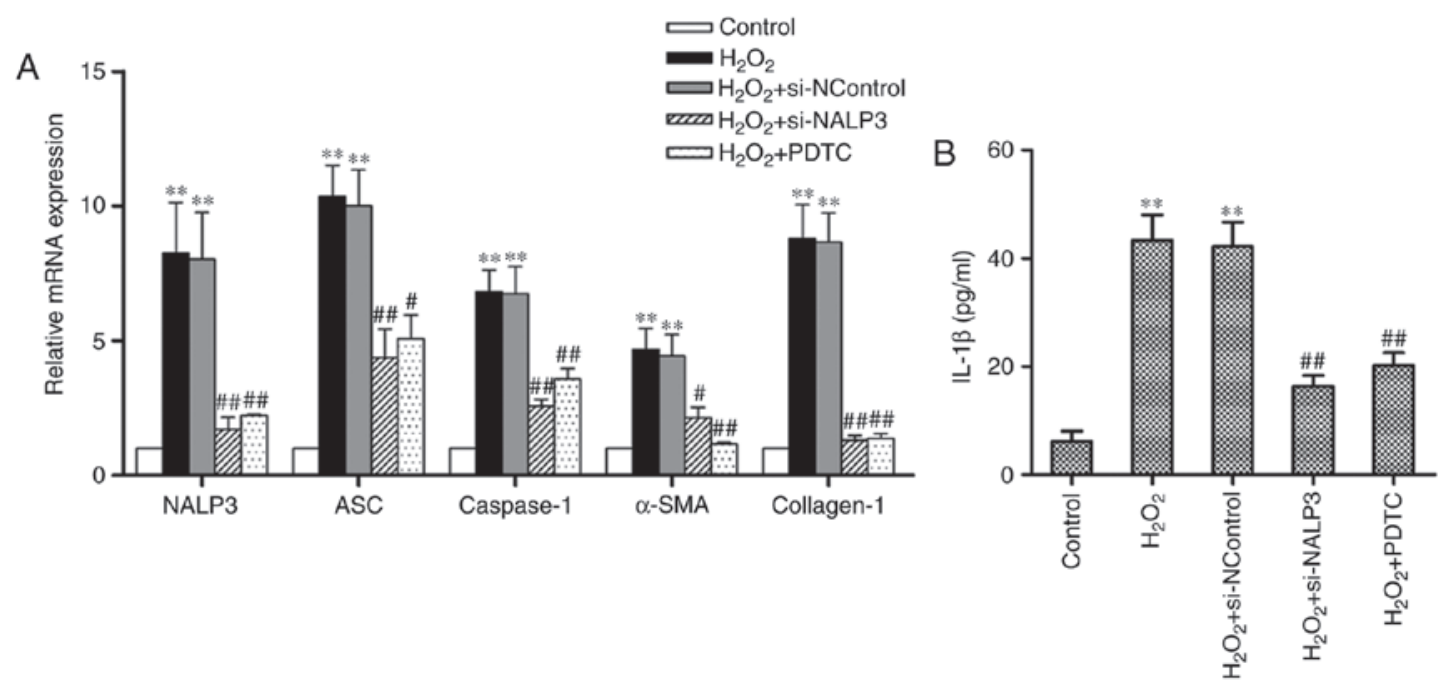

Figure 2. NALP3 gene silencing reduces NALP3 inflammasome activation during $\mathrm{H}_{2} \mathrm{O}_{2}$-mediated oxidative stress and decreases gene expression of $\alpha$-SMA and type I collagen. (A) RT-PCR analysis was used to assess the relative mRNA expression of NALP3, ASC, caspase-1, $\alpha$-SMA, and collagen-1. (B) The IL-1 $\beta$ content in cell supernatants was determined using ELISA. Data are presented as the means \pm standard error of the mean from three independent experiments. The significance among groups was analyzed by one way analysis of variance. ${ }^{* *} \mathrm{P}<0.01$ vs. the control; ${ }^{\#} \mathrm{P}<0.05,{ }^{\# \#} \mathrm{P}<0.01$ vs. the $\mathrm{H}_{2} \mathrm{O}_{2}$ group. $\alpha$-SMA, $\alpha$-smooth muscle actin; RT-PCR, reverse transcription-polymerase chain reaction; ASC, apoptosis-associated Speck-like protein; IL, interleukin; NControl, negative control; PDTC, pyrrolidine dithiocarbamate.

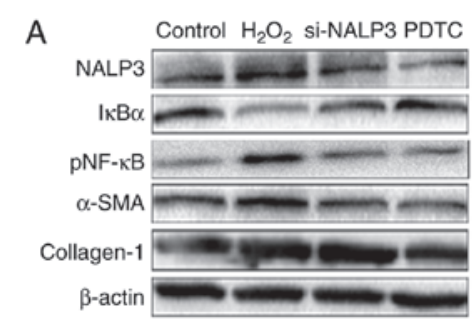

D

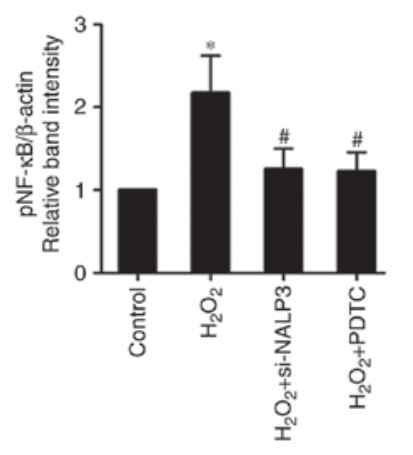

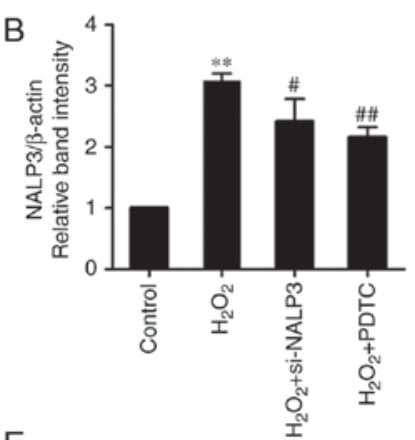

$\mathrm{E}$

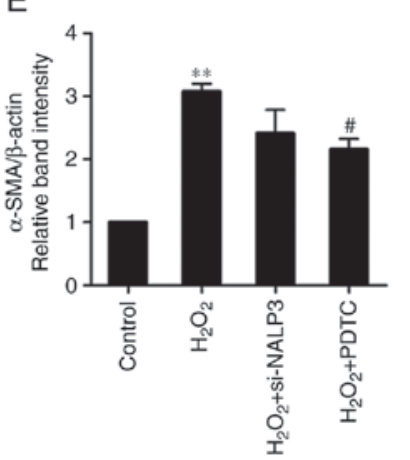

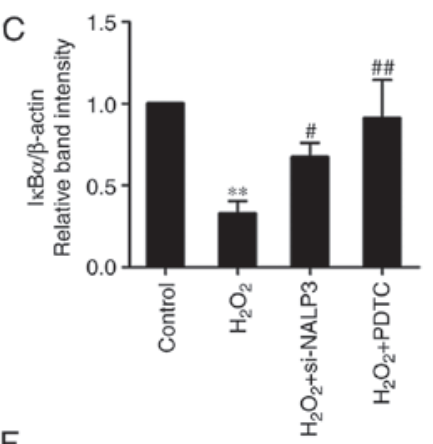

$\mathrm{F}$

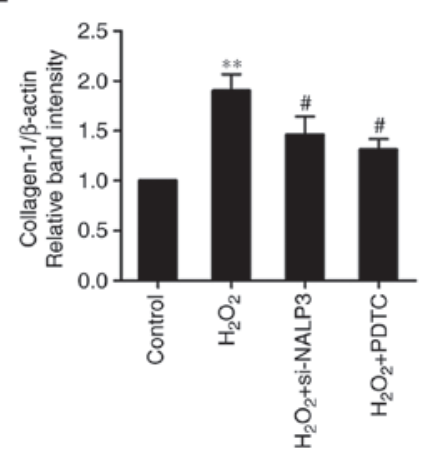

Figure 3. NALP3 inflammasome is activated during $\mathrm{H}_{2} \mathrm{O}_{2}$-induced collagen synthesis in fibroblasts via the NF- $\mathrm{kB}$ signaling pathway. (A) Protein levels of the

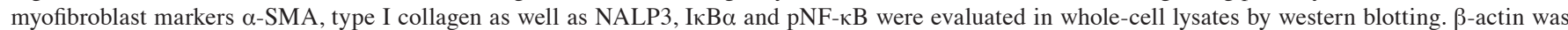
used as a loading control. (B-F) Relative protein levels were quantified by scanning densitometry and were normalized to $\beta$-actin. Data shown represent the means \pm standard error of the mean of three experiments performed in duplicate. ${ }^{*} \mathrm{P}<0.05,{ }^{* * *} \mathrm{P}<0.01$ vs. the control (treated with phosphate-buffered saline); ${ }^{\#} \mathrm{P}<0.05,{ }^{\# \#} \mathrm{P}<0.01$ vs. $\mathrm{H}_{2} \mathrm{O}_{2}$-treated cells. NF- $\kappa \mathrm{B}$, nuclear factor $\kappa \mathrm{B}$; I $\mathrm{KB} \alpha$, nuclear factor of kappa light polypeptide gene enhancer in B-cells inhibitor $\alpha$;

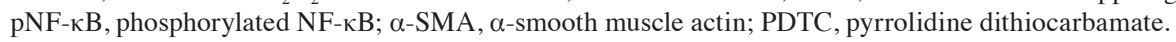

day 28 , although the fibrotic changes became more severe. These histopathological changes were improved by PDTC pretreatment (Fig. 4A).

BLM administration induced a significant increase in the Ashcroft scores compared with the control on day 7, and these scores were further increased by day 28 (Fig. 4C). Conversely, the scores of the mice administered PDTC were significantly lower. In addition, a similar trend was observed in the measurements of lung hydroxyproline content (Fig. 4B). Thus, these results indicate that the BLM-induced pulmonary fibrosis model was successfully established, and that the NF- $\kappa B$ signaling pathway played a key role in the process of fibrosis.

To examine the activation of NALP3 inflammasomes in BLM-induced pulmonary fibrosis, the mRNA levels of 

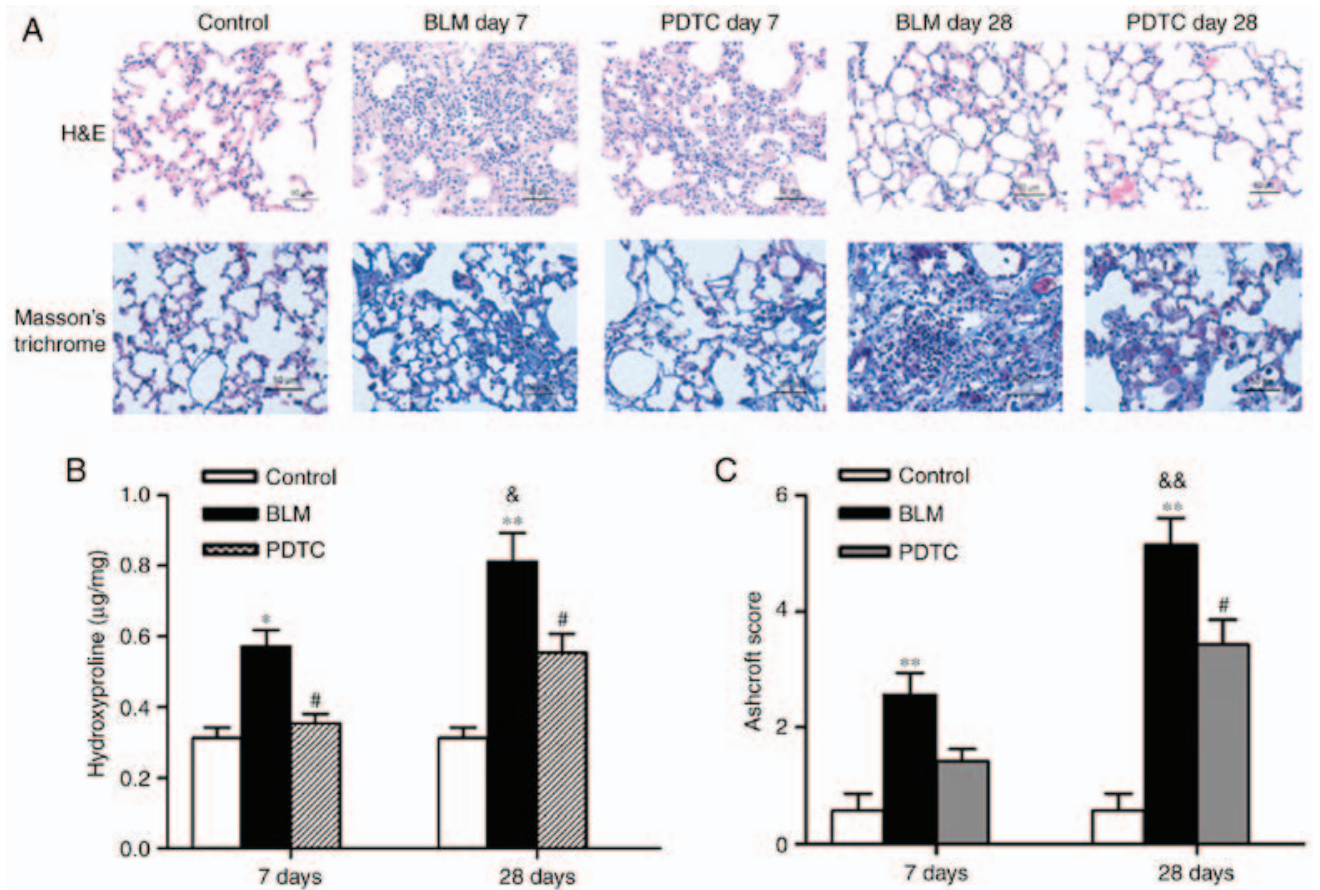

Figure 4. Suppression of the NF- $\mathrm{kB}$ signaling pathway significantly alleviates BLM-induced lung fibrosis and inflammation in mice lung tissue. (A) Paraffin-embedded sections from the lung tissues of mice were stained with H\&E or Masson's trichrome stain. Evaluation of fibrotic changes was determined via (B) hydroxyproline content and (C) Ashcroft score on day 28 after BLM administration. Results are expressed as the means \pm standard error of the mean $(\mathrm{n}=7)$. Statistical analysis was performed using one-way analysis of variance followed by Tukey's multiple comparison test. ${ }^{*} \mathrm{P}<0.05,{ }^{* * *} \mathrm{P}<0.01 \mathrm{vs}$,

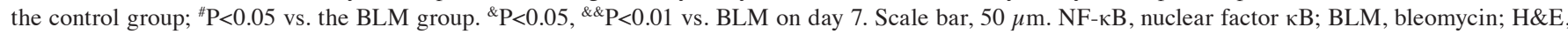
hematoxylin and eosin; PDTC, pyrrolidine dithiocarbamate.

NALP3, ASC, caspase-1, $\alpha$-SMA and type I collagen were measured and NALP3 protein levels were determined in the lungs of mice. BLM-treated mice exhibited significantly elevated levels of NALP3, ASC, caspase-1, $\alpha$-SMA and type I collagen mRNA compared with the control group when analyzed on day 28 (Fig. 5E). The level of the NALP3 protein was markedly higher compared with that of the control on both days 7 and 28, whereas NALP3 protein expression was reduced on day 28 compared with day 7 after BLM injection (Fig. 5A and B). PDTC-pretreated mice exhibited a relatively lower expression of NALP3, ASC, caspase-1, $\alpha$-SMA and type I collagen mRNA compared with the BLM group. Furthermore, PDTC reduced NALP3 protein levels to a statistically significant extent in the lungs of BLM-treated mice on days 7 and 28. In addition, ELISA analysis demonstrated that BLM administration resulted in a large increase in IL-1 $\beta$ production, and that PDTC pretreatment was able to attenuate the BLM-induced production of IL- $1 \beta$ in the lung tissues on day 28 (Fig. 5D). Western blot analysis revealed a decrease in $\mathrm{I} \kappa \mathrm{B} \alpha$ levels in the BLM group as opposed to their preservation in the BLM+PDTC group (Fig. 5A and C). However, a more significant change in the level of I $\mathrm{B} \alpha$ was not observed over time. These results suggest that the NALP3 inflammasome is activated during the stages of early inflammation and fibrosis and, therefore, may play a role in fibrogenesis.

\section{Discussion}

NALP3 has been widely investigated with respect to immune response over the past several decades, and it is considered to act as a general sensor for cellular stress. In recent years, NALP3 has been found to play important roles in various pathological processes, including diabetes mellitus $(22,23)$, non-alcoholic steatohepatitis $(24,25)$, chronic kidney diseases (26) and IPF (27). Furthermore, an increasing volume of evidence indicates that NALP3 serves as an important factor in organ fibrosis. Pulmanary fibrosis develops as a consequence of abnormalities occurring in multiple biological pathways that affect inflammation and wound repair, which involve a series of cells and cytokines. Studies on the process of fibrogenesis have focused primarily on cell injury, macrophage activation, inflammation and ECM deposition. Tian et al (28) reported that siNALP3 may rescue A549 from BLM-induced pulmonary fibrosis. Accordingly, the biological characteristics of the NALP3 inflammasome during collagen metabolism in pulmonary fibrosis remain unclear. To further elucidate the role of the NALP3 inflammasome during type I collagen synthesis in fibroblasts, the effects of NALP3-siRNA on $\mathrm{H}_{2} \mathrm{O}_{2}$-treated mouse embryonic fibroblasts were examined.

In the present study, it was suggested that NALP3 plays an important role in $\mathrm{H}_{2} \mathrm{O}_{2}$-mediated type I collagen synthesis via the NF- $\kappa \mathrm{B}$ signaling pathway. NF- $\kappa \mathrm{B}$ activation and type I collagen production were shown to be significantly decreased by NALP3-siRNA. Additionally, the inhibition of NF- $\mathrm{KB}$ resulted in downregulation of type I collagen and the NALP3 inflammasome. In addition, consistent with the results from previous studies, we demonstrated that the NALP3 inflammasome was activated in BLM-induced pulmonary fibrosis and that this activation was attenuated by PDTC.

There are two essential criteria for triggering NALP3 inflammasome activation. First, NALP3 expression per se must be transcriptionally induced, which requires NF- $\kappa B$. A 
A

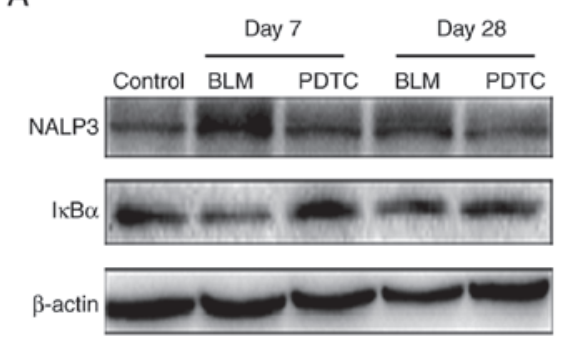

C

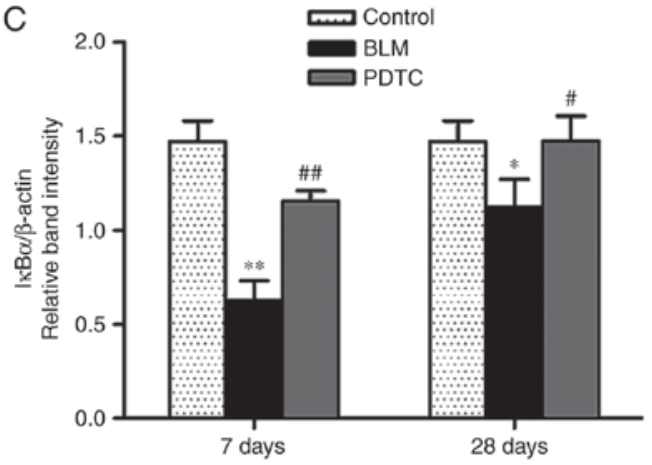

$\mathrm{E}$
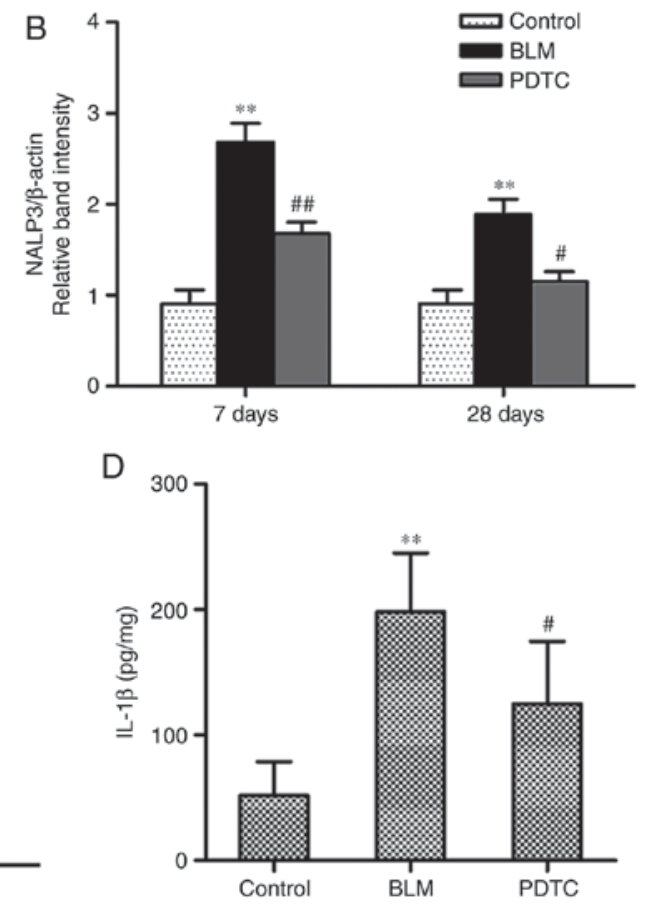

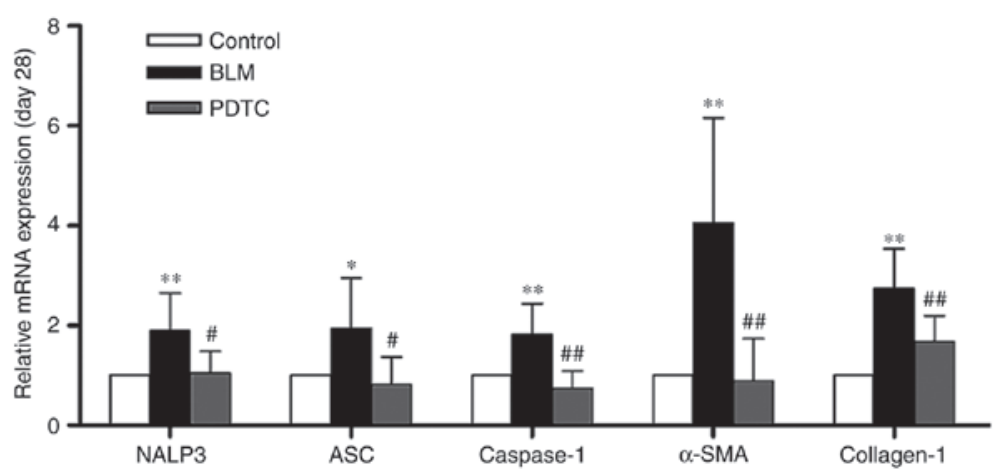

Figure 5. NALP3 inflammasome is activated in BLM-induced pulmonary fibrosis after day 28 in mice. (A-C) Protein levels of NALP3 and IкB $\alpha$ in lung tissues were determined on day 7 and day 28 by western blotting. Content of IL-1 $\beta$ in lung tissues was examined on day 28 by ELISA (D). Relative mRNA expression of NALP3, ASC, caspase-1, $\alpha$-SMA, and type I collagen (E). Data are presented as the means \pm standard error of the mean, $\mathrm{n}=7$. ${ }^{*}<0.05,{ }^{* *} \mathrm{P}<0.01$ vs. the control group at day $28 ;{ }^{\#} \mathrm{P}<0.05,{ }^{\# \#} \mathrm{P}<0.01$ vs. the BLM group at day 28 . BLM, bleomycin; I $\mathrm{B} \alpha$, nuclear factor of kappa light polypeptide gene enhancer in B-cells inhibitor $\alpha$; $\alpha$-SMA, $\alpha$-smooth muscle actin; IL, interleukin; PDTC, pyrrolidine dithiocarbamate; ASC, apoptosis-associated Speck-like protein.

second, post-transcriptional step then leads to the activation of NALP3, allowing for NALP3 inflammasome assembly. In the first step, NALP3 expression is considered as the limiting factor for inflammasome priming (29). The corresponding $\mathrm{NF}-\kappa \mathrm{B}$ binding sites (nt $-1,303$ to $-1,292$ and $-1,238$ to $-1,228$ ) are located in the NALP3 promoter in macrophages (30) and TLR2/MyD88/NF- $\kappa \mathrm{B}$ and TLR4/MyD88/NF- $\kappa \mathrm{B}$ signaling is required for pro-IL-1 $\beta$ and NALP3 gene expression (7,31). Our data further demonstrated that PDTC inhibits the expression of NALP3, ASC and caspase-1 to varying degrees. Taken together, this evidence suggests that NF- $\mathrm{KB}$ serves as a critical upstream mediator for NALP3 inflammasome priming. Accordingly, our study provides a new viewpoint regarding the NF- $\kappa \mathrm{B} /$ inflammasome pathway. The partial protection of NF- $\kappa \mathrm{B}$ activation by NALP3 silencing suggests that the inflammasome may function upstream of NF- $\kappa \mathrm{B}$. In previous studies, inflammasome activation leading to IL-1 $\beta$ maturation and release, IL-1 $\beta$ will also activate the IL-1R1/MyD88/NF- $\kappa \mathrm{B}$ pathway (10). This may contribute to an autocrine/paracrine amplification loop of IL-1 $\beta$ and NF- $\mathrm{NB}$ during the process of collagen metabolism (19).

The second criterion for triggering NALP3 inflammasome activation involves intracellular ROS and potassium $\left(\mathrm{K}^{+}\right)$efflux due to the stimulation of ATP-sensitive ion channels, which promote inflammasome assembly leading to caspase-1 activation and subsequent IL- $1 \beta$ release. Oxidative stress is a strong $\mathrm{NF}-\kappa \mathrm{B}$ activator. We thus hypothesized that oxidative stress acts both up- and downstream of the NALP3 inflammasome, and it also plays a contributory role in the pathogenesis of NALP3 inflammasome activation and pulmonary fibrosis by inducing genetic overexpression of fibrogenic cytokines (32). Artlett et al indicated that the NALP3 inflammasome plays important roles in collagen synthesis via type IA and 3A1 collagen, and connective tissue growth factor production and myofibroblast differentiation (15). Inhibition of caspase-1 abrogated the expression of collagens, IL-1 $\beta$ and $\alpha$-SMA in systemic sclerosis dermal and lung fibroblasts. As an NALP3 inflammasome effector, cytokine IL-1 $\beta$ exerts comprehensive 
biological effects associated with inflammation and fibrosis. The association between IL-1 $\beta$ and fibrosis has been widely investigated. IL-1 receptor antagonists or IL-1R deficiency may reduce liver or lung fibrosis $(10,24)$. IL-1 $\beta$ mediates collagen expression mainly via the induction of TGF- $\beta$, the downstream cytokine of IL-1 $\beta$, which is also known as the most essential cytokine in the biochemical processes of fibrosis. TGF- $\beta$ directly increases the transcriptional activation of collagen genes and also stimulates the expression of a number of proinflamatory and fibrogenic cytokines, such as TNF- $\alpha$, PDGF, IL-1 $\beta$, or IL-13, thereby further enhancing the fibrotic response in macrophages, fibroblasts and myofibroblasts. TGF- $\beta$ is also a direct mediator of epithelial-to-mesenchymal transition (EMT), which is one of the most important sources of myofibrosis. Another important TGF- $\beta$ feature in increasing ECM deposition is the creation of a microenvironment that favors ECM deposition. Redox balance modulation may affect the NALP3 inflammasome/Smad pathway in terms of collagen synthesis. Smads are the most crucial intracellular proteins that transduce extracellular signals from TGF- $\beta$ ligands to activate downstream gene transcription. Thus, the mechanism underlying collagen synthesis may be the NALP3/IL-1 $\beta /$ TGF- $\beta$ pathway. Of note, when NALP3 ${ }^{-/}$mouse primary cardiac fibroblasts (CFs) were treated with TGF- $\beta$, which plays a direct role in fibroblast differentiation into myofibroblasts and EMC deposition, they displayed impaired and delayed myofibroblast differentiation with reduced $\alpha$-SMA expression (18). Furthermore, the expression of $\alpha$-SMA and MMP-9 was significantly decreased in mouse NALP3 ${ }^{-1-}$ renal tubular epithelial cells that had been stimulated by TGF- $\beta$. Taken together, these findings may suggest an upstream role for TGF- $\beta$ to NALP3 in myofibroblast differentiation. Cai et al demonstrated that angiotensin 2 (Ang-2) increased NALP3 and pro-IL-1 $\beta$ levels by activating the TLR4/MyD88/NF- $\kappa \mathrm{B}$ pathway, and first demonstrated that Ang-2-induced collagen synthesis in hepatic stellate cells could be inhibited by NALP3 depletion. $\mathrm{NF}-\kappa \mathrm{B}$ may therefore affect inflammasome activation and downstream IL-1 $\beta$-mediated collagen metabolism.

Consistent with prior findings, our data suggest that NALP3 may act as a new mediator in the pathomechanism of fibrosis via regulating type I collagen and $\alpha$-SMA expression. NALP3 also affects the collagen synthesis rate-limiting enzyme (P4H 1 1) and collagen breakdown enzymes (MMP-2 and MMP-9) (28). However, our data demonstrated decreased mRNA expression with inhibition at the protein level of $\alpha$-SMA after transfection. A possible explanation for this apparent discrepancy is that $\mathrm{H}_{2} \mathrm{O}_{2}$-mediated myofibroblast differentiation may involve multiple pathways in which NALP3 acts upon only a subset. Another possible explanation may be associated with limitations of cell culture studies including the short duration of transfection and the transfection efficiency. To resolve this issue, we must design a more durable transfection system in our future experiment.

$\mathrm{H}_{2} \mathrm{O}_{2}$ generates excessive amounts of ROS, and both factors represent the primary mediators of the effects of TGF- $\beta$ in various cells (33-35). In particular, $\mathrm{H}_{2} \mathrm{O}_{2}$-mediated collagen synthesis is associated with TGF- $\beta$ (36). The association between NALP3 inflammasome and TGF- $\beta$ is mentioned above. Notably, the TGF- $\beta$ effects involving NALP3 have been identified as occurring in another inflammasome-independent manner. The involvement of NALP3 in TGF- $\beta$-induced R-Smad phosphorylation, nuclear accumulation and myofibroblast differentiation was demonstrated; however, TGF- $\beta$ did not induce the upregulation or secretion of activated IL-1, IL-18, or caspase-1 in CFs. By contrast, the protective effect of NALP3 deficiency was consistently reported; simultaneously, IL-1 $\beta$, IL-18, ASC, and caspase- 1 were shown to be less important under certain conditions $(37,38)$. It was suggested that ASC can induce MAPK phosphorylation independently of cytokine production in macrophages (39) to regulate mRNA stability; this, in turn, affected DOCK-2 protein expression and phagocytosis in leukocytes (40). These findings demonstrated that the physiological roles of NALP3 and ASC are not limited to the caspase-1/IL-1 $\beta$ axis. As TGF- $\beta$ represents one of the most critical cytokines in the EMT and in ECM deposition, whether the associated regulatory mechanisms involving both NALP3 and TGF- $\beta$ act via an inflammasome-dependent or -independent manner remains unclear. The independent biological effects of these components were mainly reported in non-monocytes/macrophages, such as renal tubular epithelial cells or CFs; thus, we may infer that the inflammasome-independent pathway may be a mechanism distinguishing epithelial cell lines from monocytes/macrophages, but this hypothesis requires further investigation.

As TGF- $\beta$ represents one of the most critical cytokines in EMT and in ECM deposition, whether the associated regulatory mechanisms involving both NALP3 and TGF- $\beta$ act in an inflammasome-dependent or -independent manner remains unclear.

In the present study, it was first demonstrated that NALP3 deficiency alleviates $\mathrm{H}_{2} \mathrm{O}_{2}$-induced type I collagen synthesis via the $\mathrm{NF}-\kappa \mathrm{B}$ signaling pathway. However, further research is required to identify the exact mechanism through which the NALP3 inflammasome plays a role in collagen production. As fibroblast activation represents the main checkpoint for ECM deposition, these results suggest that modulation of the effects of the NALP3 inflammasome on fibroblasts may have important therapeutic implications in pulmonary fibrosis.

\section{Acknowledgements}

The present was supported by a grant from the Sichuan Provincial Department of Science and Technology (no. 0040205301A53).

\section{Competing interests}

The authors declare that they have no competing interests.

\section{References}

1. Harari S and Caminati A: IPF: New insight on pathogenesis and treatment. Allergy 65: 537-553, 2010.

2. Latz E, Xiao TS and Stutz A: Activation and regulation of the inflammasomes. Nat Rev Immunol 13: 397-411, 2013.

3. Hillegass JM, Miller JM, MacPherson MB, Westbom CM, Sayan M, Thompson JK, Macura SL, Perkins TN, Beuschel SL, Alexeeva V, et al: Asbestos and erionite prime and activate the NLRP3 inflammasome that stimulates autocrine cytokine release in human mesothelial cells. Part Fibre Toxicol 10: 39, 2013.

4. Peeters PM, Eurlings IM, Perkins TN, Wouters EF, Schins RP, Borm PJ, Drommer W, Reynaert NL and Albrecht C: Silica-induced NLRP3 inflammasome activation in vitro and in rat lungs. Part Fibre Toxicol 11: 58, 2014. 
5. Naji A, Muzembo BA, Yagyu K, Baba N, Deschaseaux F, Sensebé L and Suganuma N: Endocytosis of indium-tin-oxide nanoparticles by macrophages provokes pyroptosis requiring NLRP3-ASC-Caspase1 axis that can be prevented by mesenchymal stem cells. Sci Rep 6: 26162, 2016.

6. Sun B, Wang X, Ji Z, Wang M, Liao YP, Chang CH, Li R, Zhang $\mathrm{H}$, Nel AE and Xia T: NADPH oxidase-dependent NLRP3 inflammasome activation and its important role in lung fibrosis by multiwalled carbon nanotubes. Small 11: 2087-2097, 2015.

7. Segovia J, Sabbah A, Mgbemena V, Tsai SY, Chang TH, Berton MT, Morris IR, Allen IC, Ting JP and Bose S: TLR2/MyD88/NF- $\kappa \mathrm{B}$ pathway, reactive oxygen species, potassium efflux activates NLRP3/ASC inflammasome during respiratory syncytial virus infection. PLoS One 7: e29695, 2012.

8. Mouratis MA and Aidinis V: Modeling pulmonary fibrosis with bleomycin. Curr Opin Pulm Med 17: 355-361, 2011.

9. dos Santos G, Rogel MR, Baker MA, Troken JR, Urich D, Morales-Nebreda L, Sennello JA, Kutuzov MA, Sitikov A, Davis JM, et al: Vimentin regulates activation of the NLRP3 inflammasome. Nat Commun 6: 6574, 2015.

10. Gasse P, Mary C, Guenon I, Noulin N, Charron S, Schnyder-Candrian S, Schnyder B, Akira S, Quesniaux VF, Lagente $\mathrm{V}$, et al: IL-1R1/MyD88 signaling and the inflammasome are essential in pulmonary inflammation and fibrosis in mice. J Clin Invest 117: 3786-3799, 2007.

11. Gasse P, Riteau N, Charron S, Girre S, Fick L, Pétrilli V, Tschopp J, Lagente V, Quesniaux VF, Ryffel B and Couillin I: Uric acid is a danger signal activating NALP3 inflammasome in lung injury inflammation and fibrosis. Am J Respir Crit Care Med 179: 903-913, 2009.

12. GicquelT, Victoni T,Fautrel A, Robert S, GleonnecF, GuezingarM, Couillin I, Catros V, Boichot E and Lagente V: Involvement of purinergic receptors and NOD-like receptor-family protein 3-inflammasome pathway in the adenosine triphosphate-induced cytokinerelease frommacrophages.ClinExpPharmacolPhysiol41: 279-286, 2014

13. Hoshino T, Okamoto M, Sakazaki Y, Kato S, Young HA and Aizawa H: Role of proinflammatory cytokines IL-18 and IL-1beta in bleomycin-induced lung injury in humans and mice. Am J Respir Cell Mol Biol 41: 661-670, 2009.

14. Phan SH and Kunkel SL: Lung cytokine production in bleomycin-induced pulmonary fibrosis. Exp Lung Res 18: 29-43, 1992.

15. Artlett CM, Sassi-Gaha S, Rieger JL, Boesteanu AC, Feghali-Bostwick CA and Katsikis PD: The inflammasome activating caspase 1 mediates fibrosis and myofibroblast differentiation in systemic sclerosis. Arthritis Rheum 63: 3563-3574, 2011.

16. Martínez-Godínez MA, Cruz-Domínguez MP, Jara LJ, Domínguez-López A, Jarillo-Luna RA, Vera-Lastra O, Montes-Cortes DH, Campos-Rodríguez R, López-Sánchez DM, Mejía-Barradas CM, et al: Expression of NLRP3 inflammasome, cytokines, and cascular mediators in the skin of systemic sclerosis patients. Isr Med Assoc J 17: 5-10, 2015.

17. Wang W, Wang X, Chun J, Vilaysane A, Clark S, French G, Bracey NA, Trpkov K, Bonni S, Duff HJ, et al: Inflammasome-independent NLRP3 augments TGF- $\beta$ signaling in kidney epithelium. J Immunol 190: 1239-1249, 2013.

18. Bracey NA, Gershkovich B, Chun J, Vilaysane A, Meijndert HC, Wright JR Jr, Fedak PW, Beck PL, Muruve DA and Duff HJ: Mitochondrial NLRP3 protein induces reactive oxygen species to promote smad protein signaling and fibrosis independent from the inflammasome. J Biol Chem 289: 19571-19584, 2014.

19. Cai S, Yang R, Li Y, Ning ZW, Zhang LL, Zhou GS, Luo W, Li DH, Chen Y, Pan MX and Li X: Angiotensin-(1-7) improves liver fibrosis by regulating the NLRP3 inflammasome via redox balance modulation. Antioxid Redox Sign 24: 795-812, 2016.

20. Hübner RH, Gitter W, El Mokhtari NE, Mathiak M, Both M, Bolte H, Freitag-Wolf S and Bewig B: Standardized quantification of pulmonary fibrosis in histological samples. Biotechniques 44: 507-511, 514-517, 2008

21. Zhang Q, Lenardo MJ and Baltimore D: 30 Years of NF- $\mathrm{B}$ : A blossoming of relevance to human pathobiology. Cell 168: 37-57, 2017.

22. Henriksbo BD, Lau TC, Cavallari JF, Denou E, Chi W, Lally JS, Crane JD, Duggan BM, Foley KP, Fullerton MD, et al: Fluvastatin causes NLRP3 inflammasome-mediated adipose insulin resistance. Diabetes 63: 3742-3747, 2014.
23. Luo B, Li B, Wang W, Liu X, Xia Y, Zhang C, Zhang M, Zhang Y and An F: NLRP3 gene silencing ameliorates diabetic cardiomyopathy in a type 2 diabetes rat model. PLoS One 9: e104771, 2014.

24. Wree A, Eguchi A, McGeough MD, Pena CA, Johnson CD, Canbay A, Hoffman HM and Feldstein AE: NLRP3 inflammasome activation results in hepatocyte pyroptosis, liver inflammation, and fibrosis in mice. Hepatology 59: 898-910, 2014.

25. Wree A, McGeough MD, Peña CA, Schlattjan M, Li H, Inzaugarat ME, Messer K, Canbay A, Hoffman HM and Feldstein AE: NLRP3 inflammasome activation is required for fibrosis development in NAFLD. J Mol Med 92: 1069-1082, 2014

26. Vasileiou E, Montero RM, Turner CM and Vergoulas G: P2X receptor at the heart of disease. Hippokratia 14: 155-163, 2010.

27. Lasithiotaki I, Giannarakis I, Tsitoura E, Samara KD, Margaritopoulos GA, Choulaki C, Vasarmidi E, Tzanakis N, Voloudaki A, Sidiropoulos P, et al: NLRP3 inflammasome expression in idiopathic pulmonary fibrosis and rheumatoid lung. Eur Res J 47: 910-918, 2016

28. Tian R,Zhu Y, Yao J, Meng X, Wang J, Xie H and Wang R: NLRP3 participates in the regulation of EMT in bleomycin-induced pulmonary fibrosis. Exp Cell Res 357: 328-334, 2017.

29. Simard J, Cesaro A, Chapeton-Montes J, Tardif M, Antoine F, Girard D and Tessier PA: S100A8 and S100A9 induce cytokine expression and regulate the NLRP3 inflammasome via ROS-dependent activation of NF- $\mathrm{B}^{1}$. PLoS One 8: e72138, 2013

30. Qiao Y, Wang P, Qi J, Zhang L and Gao C: TLR-induced NF- $\kappa$ B activation regulates NLRP3 expression in murine macrophages. FEBS Lett 586: 1022-1026, 2012

31. Bauernfeind FG, Horvath G, Stutz A, Alnemri ES, MacDonald K, Speert D, Fernandes-Alnemri T, Wu J, Monks BG, Fitzgerald KA, et al: Cutting edge: NF-kappaB activating pattern recognition and cytokine receptors license NLRP3 inflammasome activation by regulating NLRP3 expression. J Immunol 183: 787-791, 2009.

32. Poli G and Parola M: Oxidative damage and fibrogenesis. Free Radic Biol Med 22: 287-305, 1997.

33. Hong YH, Peng HB, La Fata V and Liao JK: Hydrogen peroxide-mediated transcriptional induction of macrophage colony-stimulating factor by TGF-beta1. J Immunol 159: 2418-2423, 1997.

34. Junn E, Lee KN, Ju HR, Han SH, Im JY, Kang HS, Lee TH, Bae YS, Ha KS, Lee ZW, et al: Requirement of hydrogen peroxide generation in TGF-beta 1 signal transduction in human lung fibroblast cells: Involvement of hydrogen peroxide and $\mathrm{Ca}^{2+}$ in TGF-beta 1-induced IL-6 expression. J Immunol 165: 2190-2197, 2000

35. Koo HY, Shin I, Lee ZW, Lee SH, Kim SH, Lee CH, Kang HS and $\mathrm{Ha}$ KS: Roles of RhoA and phospholipase $\mathrm{A}_{2}$ in the elevation of intracellular $\mathrm{H}_{2} \mathrm{O}_{2}$ by transforming growth factor-beta in Swiss 3T3 fibroblasts. Cell Signal 11: 677-683, 1999.

36. Park SK, Kim J, Seomun Y, Choi J, Kim DH, Han IO, Lee EH, Chung SK and Joo CK: Hydrogen peroxide is a novel inducer of connective tissue growth factor. Biochem Biophys Res Commun 284: 966-971, 2001.

37. Mizushina Y, Shirasuna K, Usui F, Karasawa T, Kawashima A, Kimura H, Kobayashi M, Komada T, Inoue Y, Mato N, et al: NLRP3 protein deficiency exacerbates hyperoxia-induced lethality through Stat3 protein signaling independent of interleukin-1ß. J Biol Chem 290: 5065-5077, 2015.

38. Shigeoka AA, Mueller JL, Kambo A, Mathison JC, King AJ, Hall WF, Correia Jda S, Ulevitch RJ, Hoffman HM and McKay DB: An inflammasome-independent role for epithelial-expressed Nlrp3 in renal ischemia-reperfusion injury. J Immunol 185: 6277-6285, 2010

39. Taxman DJ, Holley-Guthrie EA, Huang MT, Moore CB, Bergstralh DT, Allen IC, Lei Y, Gris D and Ting JP: The NLR adaptor ASC/PYCARD regulates DUSP10, mitogen-activated protein kinase (MAPK), and chemokine induction independent of the inflammasome. J Biol Chem 286: 19605-19616, 2011.

40. Ippagunta SK, Malireddi RK, Shaw PJ, Neale GA, Vande Walle L, Green DR, Fukui Y, Lamkanfi $M$ and Kanneganti TD: The inflammasome adaptor ASC regulates the function of adaptive immune cells by controlling Dock2-mediated Rac activation and actin polymerization. Nat Immunol 12: 1010-1016, 2011. 